С. М. Снигирев, к.б.н., ст. науч. сотр.

Региональный центр интегрированного мониторинга и экологических исследований, ул. Маяковского, 7, Одесса, 65082, Украина, тел.: (048) 799-62-07, e-mail: snigirev@te.net.ua

\title{
ПИТАНИЕ ПЕЛАГИЧЕСКИХ ВИДОВ РЫБ ПРИБРЕЖНЫХ ВОД О. ЗМЕИНЫЙ (ЧЕРНОЕ МОРЕ)
}

\begin{abstract}
Приведены результаты исследований некоторых аспектов биологии и экологии четырех массовых пелагических видов рыб: хамсы Engraulis encrasicolus (L., 1758), атерины Atherina pontica (Eichwald, 1831), луфаря Pomatomus saltatrix (L., 1766) и ставриды Trachurus mediteraneus ponticus Aleev, 1956 в прибрежных водах острова Змеиный (Черное море). Представлена их размерно-массовая характеристика, качественный и количественный состав питания. Приведены индексы наполненности кишечника, относительной значимости и сходства пищевых объектов.
\end{abstract}

Ключевые слова: остров Змеиный, пелагические рыбы, питание, Черное море.

Несмотря на сокращение рыбных запасов Черного моря, короткоцикличные пелагические рыбы, такие как хамса Engraulis encrasicolus (L., 1758), шпрот Sprattus sprattus (L., 1758), атерина Atherina pontica (Eichwald, 1831), ставрида Trachurus mediteraneus ponticus Aleev, 1956 и некоторые другие виды, по-прежнему остаются основными объектами промысла Украины и других причерноморских стран $[7,10]$. Северо-западная часть Черного моря в пределах Украины является наиболее важной для воспроизводства и нагула этих видов рыб [7]. При этом особое значение для пополнения рыбных ресурсов представляют собой районы, подверженные наименьшей антропогенной нагрузке. Именно на таких участках сохранились нетрансформированные, высокопродуктивные и вместе с тем наиболее уязвимые ихтиоценозы. К одним из немногих таких районов в северо-западной части Черного моря относятся прибрежные воды о. Змеиный. Согласно последним исследованиям, у острова отмечены большие скопления пелагических и донных рыб. Этот район выгодно отличается биоразнообразием ихтиофауны. Видовой состав рыбного сообщества прибрежных вод острова изучен достаточно полно $[8,12]$. Малоизученными остаются аспекты биологии и экологии отдельных видов рыб этого района. Такие исследования приобретают особую актуальность в свете внедрения в причерноморских странах рамочной директивы морской стратегии. Это определило цель данной работы - изучить питание хамсы, атерины, луфаря и ставриды в прибрежных водах о. Змеиный. 


\section{Материал и методы исследований}

Материал собран в прибрежных водах о. Змеиный в 2003, 2012, 2014 гг. в рамках международного проекта FP7 No. 287600 «PERSEUS» и при финансовой поддержке Министерства образования и науки Украины. Лов рыбы проводили сетями, ловушками, вентерями и крючковыми снастями. Для более детального изучения питания рыб в районе исследований выбраны наиболее массовые виды: хамса, атерина, луфарь и ставрида. Выловленная рыба подвергалась полному биологическому анализу по общепринятым методикам $[3,6]$. При проведении исследований измеряли общую длину (см), массу тела рыбы (г), определяли её пол, степень наполнения желудка (кишечника). Для последующей камеральной обработки пищеварительные тракты рыб фиксировали 4\% формальдегидом. Возраст особей всех изучаемых видов определяли по отолитам. Таксономическая принадлежность объектов питания рыб приведена по [4].

Значение объектов питания в пищевых рационах рыб рассчитывали по общепринятым формулам [3, $6,9,11]$ :

Индекс относительной значимости (ИОЗ), \% $=\left(N_{i} \%+P_{i} \%\right) \cdot F_{i} \%$,

где $N_{i}$ - количество $i$-объекта питания в рационе рыб; $P_{i}-$ масса $i$-объекта питания в рационе рыб, $F_{i}$ - частота встречаемости $i$-объекта питания в желудках (кишечниках) рыб.

Индекс видового сходства (ИВС), $\%=100 \cdot C \div(A+B)-C$,

где $A$ - количество таксонов объектов питания в рационе одной рыбы, $B-$ количество таксонов объектов питания в рационе другой рыбы, $C$ - количество общих таксонов объектов питания в рационах сравниваемых рыб.

Индекс пищевого сходства (ИПС), определяли как сумму минимальных значений масс (\%) общих объектов питания в рационах сравниваемых рыб.

Интенсивность питания рыб рассчитывали соответственно по общему индексу наполнения кишечника (ОИНК), ${ }_{000}=10000 \cdot p \div P$,

где $p$ - масса пищевого комка (г), $P$ - масса рыбы (г).

\section{Результаты исследований и их обсуждение}

В течение 2003-2014 гг. в прибрежных водах о. Змеиный обнаружено 65 видов морских, солоноватоводных, проходных и пресноводных рыб, принадлежащих к 17 отрядам, 40 семействам, 54 родам. Анализ эколого-фаунистической характеристики ихтиофауны прибрежных вод показал, что большинство видов $(80,0 \%)$ ведут донный и придонный образ жизни. Группа пелагических рыб представлена гораздо меньшим количеством видов (13 видов - 20,0 \%), из которых хамса, атерина, луфарь и ставрида образуют у острова плотные скопления $[8,12]$.

Средние величины общей длины и массы рыб, а также интенсивности питания по ОИНК хамсы, атерины, луфаря и ставриды приведены в табл. 1. 
Интенсивность питания у всех четырех видов рыб в прибрежных водах о. Змеиный была достаточно высокой, доля особей с пустыми желудками (кишечниками) в уловах не превышала 25,0\%. Наибольшие величины ОИНК отмечены в осенний период нагула рыб (табл. 1).

Таблица 1

Размерно-массовая характеристика, общего индекса наполнения кишечника пелагических рыб в прибрежных водах о. Змеиный

\begin{tabular}{|c|c|c|c|c|c|}
\hline \multirow{3}{*}{ Вид рыбы (возраст) } & \multirow{3}{*}{ Показатель } & \multicolumn{4}{|c|}{ Период исследований } \\
\hline & & \multicolumn{2}{|c|}{2013 г. } & \multicolumn{2}{|c|}{2014 г. } \\
\hline & & осень & Зима & весна & Осень \\
\hline \multirow{4}{*}{ E. encrasicolus (2) } & $\mathrm{L}, \mathrm{cm}$ & $11,6 \pm 0,3$ & $10,5 \pm 0,1$ & $11,6 \pm 0,1$ & $10,9 \pm 0,3$ \\
\hline & $\mathrm{m}, \Gamma$ & $11,3 \pm 0,6$ & $9,2 \pm 0,2$ & $9,5 \pm 0,3$ & $8,1 \pm 0,8$ \\
\hline & ОИНК, $\%$ & $30,7 \pm 7,4$ & $10,6 \pm 5,1$ & $59,2 \pm 11,7$ & $67,6 \pm 37,2$ \\
\hline & n, эКЗ. & 7 & 16 & 55 & 14 \\
\hline \multirow{4}{*}{ A. pontica (2) } & $\mathrm{L}, \mathrm{cm}$ & - & - & $7,6 \pm 0,2$ & $8,8 \pm 0,3$ \\
\hline & $\mathrm{m}, \Gamma$ & - & - & $3,1 \pm 0,2$ & $4,9 \pm 0,6$ \\
\hline & ОИНК, $\%$ & - & - & $101,3 \pm 22,4$ & $126,5 \pm 47,8$ \\
\hline & n, экз. & - & - & 30 & 17 \\
\hline \multirow{4}{*}{ P. saltatrix (1) } & $\mathrm{L}, \mathrm{cm}$ & $18,7 \pm 0,3$ & - & - & $19,7 \pm 0,4$ \\
\hline & $\mathrm{m}, \Gamma$ & $67,0 \pm 3,9$ & - & - & $79,6 \pm 4,3$ \\
\hline & ОИНК, $\%$ & $216,9 \pm 22,4$ & - & - & $104,2 \pm 15,2$ \\
\hline & n, экз. & 29 & - & - & 22 \\
\hline \multirow{4}{*}{ T. m. ponticus (3) } & $\mathrm{L}, \mathrm{cm}$ & $14,1 \pm 0,1$ & - & $15,6 \pm 0,3$ & $17,0 \pm 0,4$ \\
\hline & $\mathrm{m}, \Gamma$ & $25,7 \pm 0,9$ & - & $37,0 \pm 2,4$ & $47,5 \pm 4,1$ \\
\hline & ОИНК, $\%$ & $186,3 \pm 34,3$ & - & $208,1 \pm 31,5$ & $241,0 \pm 67,2$ \\
\hline & n, эКз. & 18 & - & 30 & 6 \\
\hline
\end{tabular}

Примечание: L - общая длина рыбы, m - масса рыбы, $\mathrm{n}$ - число особей,

В рационе хамсы в прибрежных водах острова обнаружены организмы, принадлежащие к 15 таксонам (табл. 2). Наиболее значимыми в питании оказались коловратки и копеподы, а также организмы бентопланктона: полихеты, амфиподы и мизиды (табл. 2). Как известно, в условиях недостаточного количества зоопланктона, вынужденной пищей хамсы является фитопланктон [2]. В период исследований у о. Змеиный доля фитопланктона в рационе хамсы составляла от 3,8 до 78,0 \% от общей массы пищевого комка. Наиболее часто организмы фитопланктона отмечены в кишечниках хамсы зимой (табл. 2). 
Таблица 2

Величины индекса относительной значимости (\%) объектов питания хамсы и атерины в прибрежных водах о. Змеиный

\begin{tabular}{|c|c|c|c|c|c|c|}
\hline \multirow{3}{*}{ Объекты питания } & \multicolumn{4}{|c|}{ Хамса } & \multirow{2}{*}{\multicolumn{2}{|c|}{$\begin{array}{c}\text { Атерина } \\
2014 \text { г. }\end{array}$}} \\
\hline & \multicolumn{2}{|c|}{2013 г. } & \multicolumn{2}{|c|}{2014 г. } & & \\
\hline & осень & зима & весна & осень & весна & Осень \\
\hline Polychaeta gen. sp. & 3667,6 & - & 2579,4 & 2986,8 & 1994,3 & 4045,4 \\
\hline Polychaeta larv. & - & - & 23,2 & - & - & - \\
\hline Rotatoria gen. sp. & - & 102,5 & 486,2 & - & - & - \\
\hline Penilia avirostis & - & 98,7 & 8,5 & - & 4,4 & - \\
\hline Pseudocalanus elorsata & 835,8 & 822,2 & 28,0 & 450,5 & 545,2 & 154,9 \\
\hline Paracalanus parvus & - & - & - & - & 4,4 & - \\
\hline Calanus ponticus & - & - & - & - & 8,8 & 23,6 \\
\hline Acartia gen. sp. & - & 284,6 & 3,8 & 32,2 & 17,4 & - \\
\hline Idoteiidae gen. sp. & - & - & - & - & 7,0 & - \\
\hline Sphaeromatidae gen. sp. & - & - & - & - & 44,5 & - \\
\hline Gammaridae gen. sp. & 663,1 & - & 102,1 & - & 67,6 & 41,0 \\
\hline Microdeutopus gen. sp. & - & - & - & - & 4,7 & 144,0 \\
\hline Corophiidae gen. sp. & - & 560,1 & 151,4 & 698,6 & 871,5 & 180,7 \\
\hline Stenothoe gen. sp. & - & - & - & 38,6 & 305,0 & 27,6 \\
\hline Cumacea gen. sp. & - & - & - & - & - & 185,6 \\
\hline Mysidacea gen. sp. & - & 209,8 & 2600,2 & 824,2 & 101,5 & 858,4 \\
\hline Athanas nitescens & - & - & - & - & 93,3 & 25,6 \\
\hline Palaemon elegans & - & - & - & - & 94,3 & - \\
\hline Balanus larv. & - & - & 3,8 & - & - & - \\
\hline Decapoda larv. & - & - & 1,7 & - & - & - \\
\hline Bivalvia larv. & - & - & 6,7 & - & - & - \\
\hline Икра рыб & - & - & 21,9 & - & 64,7 & - \\
\hline $\begin{array}{l}\text { Фитопланктон, \% от массы } \\
\text { пищевого комка }\end{array}$ & 48,5 & 78,0 & 3,8 & 9,8 & - & - \\
\hline
\end{tabular}

Рацион атерины включал 17 таксонов кормовых объектов. Из них в питании преобладали полихеты, амфиподы, мизиды (табл. 2). Также существенную роль в питании играли планктонные ракообразные (табл. 2). Согласно данным, полученным в летний период 2009 г., у проанализированных особей атерины в питании преобладали планктонные копеподы, составляя до 45,0 \% массы пи- 
щевого комка. Доля пелагических личинок десятиногих ракообразных, моллюсков и полихет была незначительна [5].

Сравнительный анализ рационов хамсы и атерины прибрежных вод о. Змеиный показал незначительное сходство (ИВС - 39,1 \%). С другой стороны, высокие значения величины и ИПС (70,0 \%) свидетельствовали о сходных пищевых предпочтениях сравниваемых рыб, выраженных в интенсивном потреблении ими полихет.

Спектр питания особей луфаря прибрежных вод о. Змеиный представлен 8 объектами. В пищевых комках доминировали рыбы: хамса, ставрида, атерина, шпрот и мерланг. В 2003 г. в прибрежных водах острова в желудках луфаря найдены также остатки креветки каменной Palaemon elegans (табл. 3).

В ходе исследований установлено, что рацион ставриды включал организмы, принадлежащие к 16 таксонам. Главной ее пищей возле острова была рыба (табл. 3). В 2013 и 2014 гг. значительную долю в питании также составляли полихеты и ракообразные (Amphipoda, Isopoda). У крупных особей в пищевых комках отмечена собственная молодь, значение которой в питании было достаточно велико (ИОЗ - 295,9-492,1 \%).

Таблица 3

Величины индекс относительной значимости (\%) объектов питания луфаря и ставриды в прибрежных водах о. Змеиный

\begin{tabular}{|c|c|c|c|c|c|c|c|c|c|}
\hline \multirow{3}{*}{ Объекты питания } & \multicolumn{4}{|c|}{ Луфарь } & \multicolumn{5}{|c|}{ Ставрида } \\
\hline & 2003 r. & 2012 г. & 2013 г. & 2014 г. & 2003 г. & 2012 г. & 2013 г. & 2014 г. & 2014 г. \\
\hline & лето & лето & Осень & осень & лето & лето & осень & весна & осень \\
\hline Polychaeta gen. sp. & - & - & - & - & - & - & 2710,0 & 3295,7 & 2803,2 \\
\hline Amphipoda gen. sp. & - & - & - & - & 1,4 & 1,9 & 1588,9 & 2005,3 & 2527,5 \\
\hline Isopoda gen. sp. & - & - & - & - & 1,2 & 2,7 & 180,7 & 20,3 & 165,3 \\
\hline Athanas nitescens & - & - & - & - & - & - & 13,9 & 76,3 & - \\
\hline Palaemon elegans & 11,1 & - & - & - & 245,4 & 28,9 & 267,2 & 45,0 & - \\
\hline Gymnammodytes cicerellus & - & - & 48,6 & - & - & - & 98,3 & 29,2 & - \\
\hline Engraulis encrasicholus & 260,2 & 1024,7 & 1083,7 & 788,5 & 450,6 & 752,4 & 629,2 & 792,0 & 409,3 \\
\hline Sprattus sprattus phalericus & - & 120,5 & 100,1 & - & 153,3 & 247,4 & 174,2 & - & - \\
\hline Merlangius merlangus euxinus & 78,4 & 189,2 & 39,5 & - & 58,1 & - & - & - & - \\
\hline Atherina pontica & - & 36,6 & 52,2 & 74,8 & 79,5 & 52,3 & 53,8 & 5,5 & - \\
\hline $\begin{array}{l}\text { Trachurus mediteraneus } \\
\text { ponticus }\end{array}$ & - & 85,1 & 6081,1 & 4705,1 & - & - & - & 295,9 & 492,1 \\
\hline Pisces gen. $\mathrm{Sp}$ & & & 643,7 & 2500,0 & - & - & 179,6 & 176,5 & 1585,0 \\
\hline $\begin{array}{l}\text { Число таксонов объектов } \\
\text { питания }\end{array}$ & 3 & 5 & 7 & 4 & 7 & 6 & 12 & 12 & 8 \\
\hline
\end{tabular}


Величины ИПС $(70,4 \%)$ и ИВС $(50,0 \%)$ кормовых объектов в рационах ставриды и луфаря были достаточно высокими, что указывает на сходное питание этих двух видов.

Таким образом, полученные нами результаты совпадают с данными литературы, согласно которых хамса и атерина являются преимущественно зоопланктонофагами с широким спектром питания, куда входят организмы меропланктона и бентопланктона $[1,2]$.

В современных условиях увеличения численности и распространения хищного гребневика Mnemiopsis leidyi A. Agassiz, 1865 в Черном море, подорвавшего кормовую базу планктоноядных рыб, значение бентопланктонных организмов, вероятно, будет возрастать в питании планктоноядных рыб.

Главную роль в питании ставриды и луфаря в прибрежных водах острова, как и на других участках Черного моря [1], составляют разные виды рыб. Ставрида в прибрежных водах острова также активно потребляет разноногих ракообразных и полихет.

\section{Выводы}

1. В рационах хамсы и атерины обнаружены организмы, принадлежащие к 15 и 17 таксонам соответственно. Наиболее значимыми в питании хамсы были полихеты, разноногие ракообразные, мизиды, коловратки и зоопланктонные ракообразные (преимущественно Copepoda). Зимой хамса в большей степени потребляет фитопланктон. В питании атерины преобладали полихеты, амфиподы, мизиды. Второстепенную роль играли планктонные ракообразные.

2. В питании луфаря и ставриды отмечено 8 и 16 таксонов соответственно. В пищевых комках этих видов доминировали рыбы. Важной составляющей рациона ставриды были также полихеты и амфиподы.

3. Рацион луфаря и ставриды (ИПС $-70,4 \%$, ИВС - 50,0 \%) свидетельствует о значительном сходстве их питания. Совпадение спектров питания хамсы и атерины менее значительно (ИПС - 70,0 \%, ИВС - 39,1\%)

\section{Благодарности}

Исследования проводились в рамках научно-исследовательских работ, финансируемых Министерством образования и науки Украины (2003-2014 гг.), а также при поддержке проекта FP7 No. 287600 «PERSEUS».

\section{Список использованной литературы}

1. Васильева Е. Д. Рыбы черного моря. Определитель морских, солоноватоводных, эвригалинных и проходных видов с цветными иллюстрациями, собранными С.В. Богородским / Е. Д. Васильева.- М.: изд-во ВНИРО, 2007. $-238 \mathrm{c}$.

2. Корнилова В. П. Питание азовской хамсы / В. П. Корнилова // Тр. ВНИРО. М.: ВНИРО, 1955. - Т. 31. Вып. 1. - С. 368-377. 
3. Методи гідроекологічних досліджень поверхневих вод / [Під ред. В. Д. Романенко]. - НАН України. Ін-т гідробіології. - К.: ЛОГОС, 2006. - 408 с.

4. Определитель фауны Черного и Азовского морей / [Под ред. Ф. Д. Мордухай-Болтовского]. - Киев: Наук. думка, 1968. - Т. 1. - 439 с., 1969. - Т. 2. - 538 с., 1972. - Т. 3. - 340 с.

5. Отчет о научно-исследовательской работе № 506 «Оцінити дострокові зміни та обгрунтувати заходи щодо стабілізації екологічного стану прибережних вод та берегової смуги острову Зміїний» (20132014). / Под ред. В. И. Мединца. - Одесса, 2014. - 409 с.

6. Пряхин Ю. В. Методы рыбохозяйственных исследований / Ю. В. Пряхин, В. А. Шкицкий. - Ростов-наДону: Изд-во ЮНЦ РАН, 2008. - 256 с.

7. Северо-западная часть Чёрного моря: биология и экология / [Под ред. Ю. П. Зайцева, Б. Г. Александрова, Г. Г. Миничевой]. - Киев: Наук. думка, 2006. - 701 с.

8. Снигирев С. М. Донная ихтиофауна прибрежных вод о. Змеиный / С. М. Снигирев.: автореф. дисс. канд. биол. наук. - К. Инт. Гидробиол. НАНУ, 2011. - 20 с.

9. Шорыгин А. А. Питание и пищевые взаимоотношения рыб Каспийского моря / А. А. Шорыгин. - М.: Пищепромиздат, 1952. - 268 с.

10. O'Higgins T. Achieving good environmental status in the Black Sea: scale mismatches in environmental management / T. O’Higgins, A. Farmer, G. Daskalov, S. Knudsen, and L. Mee // Ecology and Society, 2014. 19(3). $-54 \mathrm{p}$

11. Pinkas L. Food habits of albacore, blue tuna and bonito in California waters / L. Pinkas, M. S. Oliphant, I. L. Iverson. - Calif. Dept. Fish. Game. Fish. Bull, 1971. - 105 p.

12. Snigirov $S$. The fish community in Zmiinyi Island waters: structure and determinants / S. Snigirov, O. Goncharov, S. Sylantyev // Marine Biodiversity. - 2012. - Vol. 42, № 2. - P. 225-239.

Статья поступила в редакцию 02.05.2015

\section{С. М. Снігірьов}

Одеський національний університет імені I. І. Мечникова, Регіональний центр інтегрованого моніторингу,

вул. Маяковського, 7, Одеса, 65082, Україна, snigirev@te.net.ua;

\section{ОСОБЛИВОСТІ ЖИВЛЕННЯ ПЕЛАГІЧНИХ ВИДІВ РИБ ПРИБЕРЕЖНИХ ВОД О. ЗМІЇНИЙ (ЧОРНЕ МОРЕ).}

\section{Резюме}

У роботі наведено результати досліджень деяких аспектів біології та екології чотирьох масових пелагічних видів риб: хамси Engraulis encrasicolus (L., 1758), атерини Atherina pontica (Eichwald, 1831), луфаря Pomatomus saltatrix (L., 1766) та ставриди Trachurus mediteraneus ponticus Aleev, 1956 в прибережних водах острова Зміїний (Чорне море). Представлена їх розмірно-масова характеристика, якісний та кількісний склад живлення. Наведено індекси наповненості кишечнику, відносної значимості та подібності харчових об’єктів.

Ключові слова: острів Зміїний, пелагічні риби, живлення, Чорне море. 


\title{
S. M. Snigirov
}

Odessa National Mechnikov University

7, Mayakovsky St., Odessa, 65082, Ukraine, e-mail: snigirev@te.net.ua

\section{DIET OF PELAGIC FISHES IN THE ZMIINYI ISLAND COASTAL WATERS (THE BLACK SEA)}

\begin{abstract}
Altogether, 65 marine, brackish-water, migratory and freshwater fish species belonging to 17 orders, 40 families and 54 genera were found in the Zmiinyi Island area during 2003-2014. Most of them (80.0 \%) are bottom and demersal species. The group of pelagic fishes represented a much smaller number of species (13 species $-20.0 \%$ ). Among them anchovy, sand smelt, bluefish and horse mackerel form the dense concentrations near the Zmiinyi Island.

Diets of the following main pelagic species in the Zmiinyi Island coastal waters have been described and analysed: Black Sea anchovy Engraulis encrasicolus ponticus (Alexandrov, 1927), Black Sea sand Atherina pontica (Eichwald, 1831), bluefish Pomatomus saltatrix (L., 1766) and horse mackerel Trachurus mediteraneus ponticus Aleev, 1956. The Relative Importance Index, Food Similarity Index and Species Similarity Index of anchovy and sand, bluefish and horse mackerel have been presented.
\end{abstract}

Keywords: the Zmiinyi Island, pelagic fishes, consumption, the Black Sea. 